\title{
COVID-19 Depression- A Black Hole You Can Escape From
}

\author{
Saifullah Shaikh ${ }^{1 *}$ and Rabiya Ali² \\ ${ }^{1}$ Department of Physiology, Bahria University Medical and Dental College, Karachi, Pakistan \\ ${ }^{2}$ Department of Physiology, Karachi Institute of Medical Sciences (KIMS), CMH, Karachi, Pakistan
}

\section{Respected Editor,}

COVID-19 is the disease caused by a new coronavirus that emerged in China in December 2019. Coronavirus disease is a cluster of acute respiratory illnesses, which first occurred in Wuhan, Hubei province, then quickly spread to other regions of China and eventually the whole world. On March 11, the World health organization (WHO) declared the COVID-19 outbreak as a public health emergency characterized as a "pandemic" [1]. On $26^{\text {th }}$ February, 2020 COVID-19 was first confirmed in Pakistan. On $24^{\text {th }}$ March, the government of Pakistan announced a lockdown for the control of infection, which caused panic and stress in public [2]. It has been accepted that the method of strict quarantine measures, isolation, institutional shutdown, recent unemployment, financial crisis, and ailments all boost to increase the risk for mental distress. Furthermore, people have encountered anxiety, phases of panic attacks, depression in a wide population affecting mainly females, adolescents, and the elderly with comorbidity. It is mentioned in studies that breaking news and social media exposure has deteriorated the mental health of the general public worldwide [3]. Due to the current pandemic, front-line healthcare workers worldwide have been highly exposed to unusually, severe distressful conditions, because they are taking continuous dreadful risky decisions working under intense pressure compromising not only their lives but their families' lives as well for the sake of the nation. This may result in ethical detriment or psychological issues [4]. It has been confirmed that in addition to physical damage, COVID-19 has caused the mental health of the public to deteriorate at a much higher rate [5]. Problems of mental health that people experienced during lockdown due to financial difficulties, has ignored continually and mainly absent in the latest discourse [3].

Pakistan is an underdeveloped country, which is struggling to accelerate and most of its people belong to the lower class, the lockdown situation was severely affecting the daily routines and financial condition of these peoples. Considering this fact, the Prime minister

\footnotetext{
*Corresponding Author: Saifullah Shaikh, Department of Physiology, Bahria University Medical and Dental College, Karachi, Pakistan.

Email:dr.saif74@yahoo.com

Received: June 21, 2020; Revised: October 13, 2020; Accepted: October 31, 2020 DOI: https://doi.org/10.37184/lnjpc.2707-3521.2.9
}

lifted the lockdown till $5 \mathrm{pm}$ to facilitate the earning of a poor population. Considering these facts, we planned to highlight the presence of depressive symptoms among people in Karachi during the COVID-19 pandemic, based on a questionnaire, which was constructed to conclude whether the subject had depressive symptoms or not, the interviews were conducted through Zoom software meetings. During interviews, some people did not meet the criteria of depressive disorder because they remained focused on their mental and physical health by doing different healthy activities at home, which kept them motivated and going even through this pandemic. Other subjects fulfilled the criteria of depressive disorder because they are influenced by the critical effects of the pandemic during a lockdown and since they did not focus on their mental and physical health; they were overstressed, demotivated, and down 'felt low' through the pandemic, which wasn't working out for them.

Nationwide social distancing and isolation policies are having an unprecedented impact on our daily lives, physical activity, and health. On one side where the period of quarantine or isolation is the best option to control spread, it has developed drastic effects on other dimensions in on the isolated people's individual physical and mental health [5, 6]. Previously, physical exercises and daily outdoor activities consisted of a major proportion of the lives of people, which has changed due to the situation. These activities in many cases included a certain aim to counteract the negative consequences of some diseases like dementia, infections, respiratory diseases, and heart diseases, etc. Moreover, the psychological impact of quarantine has been negatively affecting people's mental health making people suffer from different problems like depression, anxiety, fears, frustrations, depression, anger \& boredom. Some studies of different countries revealed the most common among these is anxiety and depression. Therefore, people during this quarantine must maintain an active lifestyle at home is very important for the maintenance of their mental and physical health, especially those who have additional risk factors and older people. We should support the idea "doing some exercise is better than doing nothing". Instead of stressing out over situations, people should try to focus on things that may improve their mental and physical health. Meditating, exercising, listening to 
motivational speakers, participation in online counseling programs, and reading books will surely reduce down the bar of depression. Everyone should buckle themselves up, stay active, and try to do something productive instead of fighting with their thoughts; this will not only affect you positively, but will affect people around you as well. Our country needs to address this issue. It's high time to provide $24 / 7$ helpline services for counseling because it might save someone's life and it will not only help someone or their life but will and to create awareness about mental health.

\section{CONFLICT OF INTEREST}

The authors declare no conflict of interest.

\section{ACKNOWLEDGEMENTS}

The authors appreciate the participation of Aiman Mansoor, Dua Memon and Misha Amir who helped to facilitate the research process.

\section{REFERENCES}

1. Zhong B-L, Luo W, Li H-M, Zhang Q-Q, Liu X-G, Li W-T, et al. Knowledge, attitudes, and practices towards COVID-19 among Chinese residents during the rapid rise period of the COVID-19 outbreak: a quick online cross-sectional survey. Int J Biol Sci 2020; 16(10): 1745.

2. Salman M, Mustafa ZU, Asif N, Zaidi HA, Hussain K, Shehzadi N, et al. Knowledge, attitude and preventive practices related to COVID-19: a cross-sectional study in two Pakistani university populations. Drugs Ther Perspect 2020: 1-7. [Epub ahead of print]

3. Alvi M, Gupta M. Learning in times of lockdown: how COVID-19 is affecting education and food security in India. Food Secur 2020: 12; 793-6.

4. Zandifar A, Badrfam R. Iranian mental health during the COVID-19 epidemic. Asian J Psychiatr 2020; 51: 101990.

5. Elmer T, Stadtfeld C. Depressive symptoms are associated with social isolation in face-to-face interaction networks. Sci Rep 2020; 10(1): 1-12.

6. Menec VH, Newall NE, Mackenzie CS, Shooshtari S, Nowicki S. Examining social isolation and loneliness in combination in relation to social support and psychological distress using Canadian Longitudinal Study of Aging (CLSA) data. PloS One 2020; 15(3): e0230673. 